\title{
Democratização de políticas sociais no Brasil Venturas e desventuras das organizações da sociedade civil
}

\author{
Democratization of social policy in Brazil \\ Fortunes and misfortunes of civil society organizations \\ Armindo dos Santos de Sousa Teodósio
Graziele Andrade Resende*
}

Resumo: O artigo discute as perspectivas de democratização de políticas sociais através da descentralização no Brasil. Para tanto, faz uma discussão teórica sobre a dinâmica da descentralização de políticas públicas no contexto brasileiro e seus desdobramentos sobre a democratização das políticas sociais a partir de dois fenômenos que compõem as tentativas de modernização do estado: a difusão de conselhos municipais de políticas e a promoção de parcerias entre organizações da sociedade civil e governos para a provisão de serviços sociais. Trata-se de um artigo de natureza teórica, que recorreu a diferentes fontes bibliográficas sobre participação popular, conselhos de políticas, relações entre estado e sociedade civil e cultura política brasileira. A análise aponta a permanência de importantes desafios para a consolidação de processos políticos pautados na democracia participativa no Brasil, que acabam por reconfigurar e trazer novas dimensões para armadilhas e riscos de centralização de poder, domínio tecnocrático e expansão do clientelismo no cenário político brasileiro contemporâneo. Palavras-chave: Organizações da sociedade civil. Políticas públicas. Participação popular. Conselhos municipais. Democracia participativa.

Abstract: This paper discusses the democratization of social policies through decentralization in Brazil. The authors make a theoretical analysis of the dynamics of decentralization of public policies in the Brazilian context and its repercussions on the democratization of social policies based on two phenomena that conform the attempts to modernize the state: the diffusion of municipal councils and the promotion of partnerships between civil society organizations and governments for the provision

\footnotetext{
* Armindo S. S. Teodósio é doutor em Administração de Empresas pela FGV (São Paulo, Brasil) e professor no PPG em Administração da PUC-Minas em Belo Horizonte, MG, Brasil $<$ teodosio@pobox.com>. Graziele A. Resende é especialista em Elaboração e Gestão de Projetos pela PUC-Minas (Belo Horizonte, Brasil); atualmente é supervisora comercial da Apae Contagem em Contagem, MG, Brasil<resendegra@hotmail.com>.
} 
of social services. This is a theoretical paper that builds on different literature sources on popular participation, policy councils, relations between state and civil society and Brazilian political culture. The analysis points to the persistence of important challenges to the consolidation of political processes guided by the participatory democracy in Brazil, which eventually renew and bring new dimensions for traps and risks of centralization of power, technocratic power and expansion of the clientelism in contemporary Brazilian political reality.

Keywords: Civil society organizations. Public policies. Popular participation. Municipal councils. Participatory democracy.

\section{Introdução}

O trabalho procura analisar as interações entre estado e sociedade civil no que tange a provisão de bens e serviços sociais a partir da descentralização de políticas públicas no Brasil contemporâneo. A Constituição de 1988 representou um marco na tentativa de descentralização da gestão pública no país. A partir dela, os municípios foram instituídos de vários deveres junto à população, no que refere a prestação de serviços públicos em diferentes áreas. Essas demandas vêm se traduzindo na necessidade crescente do município se articular com instituições que, na prática, já possuem meios físicos e/ou tecnológicos para prestar tais serviços.

Importantes debates têm sido realizados sobre esse tema, envolvendo desde os riscos das organizações da sociedade civil se tornarem um braço terceirizado da ação do governo na prestação de serviços (Gómez, 2000), até se chegar à melhoria das políticas públicas, na medida em que se tornariam mais próximas do cidadão e permitissem avançar as práticas de democracia participativa no país (Arretche, 1996). Trata-se de um cenário em constante transformação devido a diferentes fatores contextuais e estruturais da cultura política brasileira, que têm adquirido maior complexidade tanto no campo das experiências concretas de gestão das políticas públicas quanto nas análises teóricas que se seguiram. Como pano de fundo dessa realidade, permanecem importantes "perguntas de pesquisa" sobre o aprofundamento da democracia participativa e a efetividade das políticas públicas. Para tanto, além da discussão teórico-conceitual, serão apresentadas e problematizadas algumas experiências no caso brasileiro, com vistas a se avançar na compreensão dessa importante fenômeno que permeia as relações entre estado e sociedade civil no Brasil.

O presente artigo é natureza teórica, recorrendo à pesquisa bibliográfica sobre temas como participação popular, relações entre estado e sociedade 
civil, natureza e papel das organizações da sociedade civil e cultura política brasileira, para tentar avançar na compreensão dos avanços e dos limites da descentralização de políticas públicas sociais no Brasil e suas implicações para a democracia participativa. A discussão divide-se em duas partes principais; uma na qual são caracterizados os principais elementos da descentralização de políticas públicas no país e outra que analisa os desafios encontrados em dois fenômenos que marcam a gestão pública brasileira contemporânea: os conselhos municipais de políticas e as parcerias entre organizações da sociedade civil e governos locais na provisão de serviços sociais. Com isso espera-se lançar novas perspectivas de compreensão de um fenômeno não apenas de relevância teórica, mas de grande importância para a sociedade brasileira, o avanço da democracia participativa em um contexto marcado pela descentralização de políticas públicas e de tentativa de reconfiguração das relações entre estado e organizações da sociedade civil.

\section{Gestão pública, descentralização de políticas públicas e participação popular}

Um desdobramento importante das tentativas de modernização do estado diz respeito à ênfase na gestão pública, buscando construir a cidadania através da participação do cidadão na busca de soluções para os problemas sociais. Para que isso ocorra, pressupõe que haja uma reorientação integral da sociedade e também o fortalecimento de suas instituições.

A reforma do estado preconiza a necessidade de novas formas de gerenciamento da coisa pública. Mesmo sabendo que as práticas ainda possuem resquícios de clientelismo, patrimonialismo e corporativismo, que representam grandes desafios para a provisão de políticas públicas, algumas alternativas de gestão pública são apresentadas como saída para a os desafios enfrentados pelo estado na contemporaneidade, dentre elas destacam-se a descentralização e a democratização da gestão e oferta de serviços públicos.

Essas formas de modernização do estado vêm ao encontro da sociedade civil em sua demanda pela ampliação da participação popular nas políticas públicas. Com isso, a ampliação dos espaços para a discussão e a definição do interesse público ganha ainda maior relevância, visto que aparecem como condição para o bom andamento dos processos de descentralização e para o bom gerenciamento das políticas públicas. A participação da sociedade na reforma, fortalecimento da capacidade governativa estatal e gestão do aparato governamental local assumem centralidade (Ferrarezi, 2002).

A descentralização é apresentada por muitos governos como um dos pontos centrais das iniciativas de modernização do estado. Implica em uma 
redefinição do papel do governo federal, para que a prestação de serviços públicos adquira maior flexibilidade e proximidade da população, trazendo ainda uma promessa de democratização dos processos que envolvem a provisão de serviços públicos (Arretche, 1996). Um dos argumentos a favor da descentralização reside na hipótese de que levaria a uma maior mobilização dos cidadãos e organizações comunitárias ou de base local, com uma consequente ampliação da participação, já que ofereceria maiores oportunidades para comportamentos políticos engajados nas discussões públicas no nível local. A participação parece ser suscitada, dentro dessa perspectiva, devido à descentralização possibilitar formas de atuação local que podem se tornar mais efetivas, no que tange ao controle sobre a agenda e sobre as ações do governo. A descentralização poderia ainda viabilizar intervenções sobre os problemas públicos mais focalizadas, através de parcerias com outras organizações que possuem atuação local, resultando assim, em uma maior capacidade de atingir os resultados propostos (Draibe, 1993).

Como se pode perceber, várias formas de parcerias entre o estado, empresas privadas e organizações da sociedade civil vêm sendo propostas na tentativa de tornar mais ágeis e eficientes o atendimento às demandas sociais. "Esses processos expressam formas novas de sociabilidade, indicando um reordenamento das relações destas partes da sociedade com o estado e a economia" (Draibe, 1993, p. 93).

Mas, de todos os entes sociais envolvidos na difícil arte de construção da democracia participativa, dois parecem mais impactados com estas novas perspectivas de atuação: os municípios, devido ao "fato de que ações no âmbito do poder local terem repercussão direta e imediata sobre o cotidiano das pessoas" (Teodósio, 2001, p. 2), e as organizações da sociedade civil devido à sua forma de intervenção local, seu conhecimento de realidades específicas e sua luta pelos direitos de diferentes grupos sociais.

É fato que essas tentativas de ampliação da democratização das atividades públicas têm se mostrado promissoras, mas há que se avaliar com cautela as perspectivas que ensejam no contexto brasileiro. Arretche (1996) chama a atenção para o esvaziamento das capacidades institucionais, administrativas e financeiras que os governos estaduais e municipais sofreram, enquanto da construção do estado nacional. É plausível se supor que a descentralização só conseguirá maiores avanços na medida em que também houver um fortalecimento do governo central em seus papéis de regulação, redução de desigualdades regionais e melhoria dos equipamentos e serviços públicos locais.

Outro risco apontado por Gómez (2000, p. 5) é o de que a sociedade civil possa se tornar um "mero braço 'terceirizado' do estado e do mercado, 
responsável pela prestação de serviços e pela consecução despolitizada do interesse geral". Tenório (1999) e Azevedo e Prates (1991) também se mostram preocupados com essa questão, afirmando que muitas organizações da sociedade civil correm o risco de se transformarem em entes privados de ação compensatória, diferentemente de sua qualificação original como ente de ação emancipatória, responsáveis por valores democráticos e de solidariedade humana na medida em que passam a se preocupar mais com sua inserção em uma cadeia de provisão de serviços públicos do que com a agenda de lutas e demandas frente ao estado para ampliação da cidadania.

Há também o risco do aprofundamento do clientelismo, entendido não apenas como sinal de atraso e de colonização do público pelo privado, como o faz Nunes (1999), mas também como sistema de trocas nas democracias de massa, como o entende Diniz (1982). Arretche (1996) argumenta que o uso clientelista de recursos públicos depende menos da escala da prestação de serviços e mais da natureza das instituições deles encarregadas, assim, nem a centralização explica o clientelismo, nem a descentralização significa sua eliminação.

Mesmo incorrendo-se em riscos, as parcerias do governo central com entes locais de execução de políticas contêm alternativas interessantes para modernização da gestão pública, podendo gerar um "círculo virtuoso", capaz de fortalecer tanto o governo central quanto os governos locais e as instituições, sem falar na efetividade que pode ser alcançada na execução de serviços públicos. É através do embate político entre governo e organizações da sociedade civil que poderá se ampliar a democracia participativa.

\section{Descentralização: possibilidades e ameaças no contexto brasileiro}

Ao longo da trajetória histórica brasileira, estado e sociedade desenvolveram relações marcadas por diferentes traços da cultura política, considerados por muitos como sinal de atraso e incompletude democrática e da própria cidadania. Patrimonialismo, clientelismo, mandonismo, nepotismo e assistencialismo seriam algumas dessas chagas que permeiam a cultura política brasileira ainda nos tempos atuais. Essa realidade desperta intensos debates acerca do suposto atraso brasileiro, muitas vezes considerado a partir de uma verdadeira idealização das chamadas democracias mais avançadas nos países centrais, e também sobre as especificidades de nossa forma de interação entre estado e sociedade civil e suas implicações para a dinâmica democrática (Nunes, 1999; Diniz, 1982; Dupas, 2003; Nogueira, 2004; Fernandes, 2007; Carvalho, 2008). 
$\mathrm{Na}$ trajetória do estado brasileiro, uma característica que se destaca é sua constituição como um "estado unitário" e centralizado. Já na era Vargas, a centralização do poder político se torna uma meta e uma medida de governo, que vai se acentuar com o período militar. Foi nesse cenário que surgiu o Sistema Brasileiro de Proteção Social, um sistema que se mostrou fragmentado, com reduzidos índices de cobertura e fragilmente financiado por iniciativas governamentais (Arretche, 1997). Essas peculiaridades do sistema acabaram por forçar um processo de reforma, já que da forma em que fora constituído, acabou por se tornar inviável devido ao seu alto custo de negociação. Dessa maneira, a descentralização do Sistema Brasileiro de Proteção Social ganhou força, o que representou uma nova estruturação do governo federal, de forma a se superar obstáculos no processo de descentralização de políticas públicas.

A descentralização do poder central iniciou-se através da implantação da municipalização do Sistema Único de Saúde, gestão no ensino fundamental, formulação de uma nova política federal de desenvolvimento urbano e a implementação das medidas preconizadas na Lei Orgânica da Assistência Social (Arretche, 1997).

Se não se pode ainda afirmar que a descentralização é uma realidade no cenário nacional, é possível dizer que o governo tem acenando para isto. Ao buscar a descentralização o governo federal tem como papel precípuo a regulação, tendo que zelar por normas, controles, fiscalização e cumprimento de obrigações contratuais.

[...] O estado não precisa, necessariamente, ser o investidor ou o operador direto, mas tem de, pelo menos, saber qual a funcionalidade dessas infraestruturas diante de um novo ciclo de desenvolvimento. Cabe principalmente ao estado definir metas de investimento, objetivos de universalização e padrões de qualidade (Barat, 2002, p. 66).

O estado deverá então vencer o grande desafio da descentralização, mesmo tendo relevantes fatores dificultadores, tais como seu tamanho territorial, a burocracia aqui instaurada e a ausência de uma tradição de controle social sobre o governo.

Para analisar a municipalização que vem ocorrendo no Brasil, primeiramente é preciso mencionar que o cenário não é positivo. Cohn (1998) defende que o modelo de ajuste estrutural e de estabilização econômico adotado acentua problemas como aumento da taxa de desemprego, deterioração de postos de trabalhos e a defasagem entre a taxa de crescimento e a possibilidade de criação de novos empregos. Ela ainda afirma que interesses dispersos 
dificultam ainda mais a conjugação de forças políticas que possam apoiar o governo central.

Mesmo diante de tal realidade, a municipalização é algo praticamente inevitável, não só por se tratar de uma estratégia política, a qual visa uma maior eficiência da gestão pública, mas também porque se mostra uma tendência positiva apoiada até mesmo pelos principais órgãos internacionais de fomento ao desenvolvimento (Cohn, 1998).

A municipalização vem ditada na constituição de 1988, a qual também formulou regras para o funcionamento das políticas e sua devida regulação. Houve a institucionalização dos diversos conselhos municipais, órgãos paritários que abriram as portas para a participação da sociedade civil na formulação e no acompanhamento da implantação das políticas. Isso caracterizou a abertura de um novo espaço público de discussão e democratização da política pública.

É claro que a simples institucionalização de tais conselhos não garante, por si só, sua real atuação. Há o risco de que esses conselhos serem dominados por uma dinâmica centrada nos interesses dos governos em detrimento da sociedade civil local, na medida em que passam a operar mais como forma de atender aos requisitos impostos pela descentralização de políticas públicas do que como espaço institucional conquistado a partir dos anseios e lutas pela ampliação de instâncias participativas (Demo, 2001; Gohn, 2001). Para que isso não ocorra, seria necessário a presença de organizações da sociedade civil combativas, independentes e que atuam de forma ativa no controle das ações dos governos, garantindo que uma democratização mais profunda se manifeste nesses espaços participativos (Silva, 2003; Gohn, 2005).

Claro está que este é um desafio presente naquelas experiências de gestão local que têm exatamente como meta mudar a qualidade dessa relação, democratizando o estado. E talvez seja exatamente essa ambiguidade que ajude a explicar a dificuldade em se dar continuidade a projetos e programas que busquem essa relação democrática entre estado e sociedade, e que dizem respeito à melhoria da qualidade de vida do cotidiano da população, em particular dos segmentos mais pobres (Cohn, 1998, p.168).

Há aqui que se fazer uma ressalva sobre o processo de municipalização que ocorre no Brasil. Deve-se caracterizá-lo, de acordo com Cohn (1998), como um processo que possui fortes marcas de desconcentração (e não de efetiva descentralização), já que há a delegação da execução de serviços públicos, sem o devido repasse da autonomia para a definição e implementação de políticas, permanecendo o poder nas mãos do governo central. 
É necessário também esclarecer que o processo de terceirização, caracterizado por parcerias entre sociedade civil e estado, não representa, $a$ priori, a substituição da ação deste, nem seu enfraquecimento; ao contrário, essas parcerias podem resultar no fortalecimento de suas ações, envolvendo também a redefinição de suas relações com a sociedade civil (Ferrarezi, 2002). Dessa forma, a terceirização visa à aproximação entre a realidade social e a implementação e execução das políticas públicas.

O cenário brasileiro torna-se, assim, um rico laboratório para análise da democratização das políticas sociais. Passa-se agora a uma análise de alguns exemplos de descentralização, seja através da atuação dos conselhos municipais ou mesmo através da construção de parcerias entre estado e organizações da sociedade civil.

\section{Conselhos municipais: entre a participação e o centralismo do governo local}

A criação dos conselhos gestores parece ser um dos pontos nevrálgicos da proposta de descentralização do estado. O que se discute é se a criação destes resultou realmente num maior controle da sociedade nas ações do governo e numa maior participação nas decisões sobre essas ações. De acordo Tatagiba (2002), existiam cerca de 2000 Conselhos de Saúde e cerca de 1500 Conselhos Sociais (Assistência Social, Direito da Criança e do Adolescente etc.) no Brasil. Esse número provavelmente já foi ultrapassado no presente ano, visto que há nos últimos tempos houve uma verdadeira "onda" de criação de conselhos, por diferentes motivos, conforme será discutido mais a frente.

A autora afirmar que podem ser encontrados três tipos de conselhos: "conselhos de programas", destinados ao acompanhamento de programas ou ações emergenciais específicas; "conselhos de políticas", ligados às políticas públicas, previstos em legislação e considerados parte integrante do sistema nacional; e "conselhos temáticos", relacionados a grandes movimentos ou temas gerais, que normalmente situam-se nos municípios enfatizando o referido tema em sua agenda. Os conselhos são órgãos paritários, institucionalmente criados como condição precípua ao repasse de recursos para estados e municípios. São vistos pelos legisladores como a forma mais prática de democratização das políticas públicas, desde que a comunidade faça parte do conselho, participe efetivamente de sua gestão e haja efetivo poder decisório compartilhado sobre as ações do governo local na área de competência do conselho (Gohn, 2001).

Tatagiba (2002) ainda apresenta os diversos riscos que podem culminar na inatividade desses conselhos. O primeiro risco apontado pela autora é referente ao exercício do conceito de paridade. Afirma que, mesmo que os 
conselhos sejam formados por números iguais de representantes do governo e da sociedade, esse equilíbrio não significa a solução para certos embates políticos.

Além de a composição entre os atores societais não ser o resultado necessário do conjunto das articulações estabelecidas no interior dos conselhos, o princípio da paridade tende, pelas próprias características de nossa cultura política, a se traduzir em vantagens para o governo, trazendo profundos desequilíbrios ao processo decisório (Tatagiba, 2002, p. 59).

O que se traduz é que, independente do número, o governo se articula de forma mais concisa, sendo, muitas vezes, vitorioso nos embates políticos sobre certas decisões. O que agrava isso é o fato das organizações que fazem parte dos conselhos ainda não reconheceram que sua força reside na articulação interna; logo, enquanto tentam obter resultados dispersos, motivados muitas vezes por práticas clientelistas de captura de recursos públicos, a capacidade de controle social do conselho pode se reduzir significativamente.

Este parece ser um grande risco. Os representantes de organizações da sociedade civil vão até os conselhos com a perspectiva de defender seus aparatos organizacionais contra os riscos de descontinuidade de acesso a recursos. Não se trata aqui de descartar a importância da proteção de intenções próprias, trata-se isso sim, de não se perder de vista a característica central dos conselhos como forma de materializar avanços na democracia participativa, a constituição de um espaço de articulação política das organizações da sociedade civil e a discussão de políticas públicas locais (Luchmann, 2011; Lavalle e Castello, 2008).

Há ainda o risco da sobrecarga de responsabilidades, impostas aos conselheiros que assumem responsabilidades intra e extraorganização ou mesmo entre diversos conselhos. Esse fato pode afetar a eficácia da atuação da organização no conselho, logo se justifica a necessidade de se analisar o custo e o benefício de cada atuação e proceder a escolha de quais conselhos realmente se deva participar (Tatagiba, 2002).

A autora ainda dedica grande parte de seu estudo para discutir a qualificação dos conselheiros e conclui que são poucos os que têm qualificação apropriada para atuar. A autora aponta vários exemplos de iniciativas que buscam superar esse problema através da capacitação dos conselheiros. Ainda assim, podem permanecer armadilhas tecnocráticas nesse processo, na medida em que o avanço da formação para atuação como conselheiro 
pode resultar na perpetuação de determinadas lideranças nessa instância de discussão de políticas públicas e seu distanciamento dos anseios das organizações comunitárias ou de base que representam (Demo, 2001; Gohn, 2001).

Outro risco notório é a possibilidade do governo de "comandar" os conselhos. Nesse ponto, torna-se mais difícil acreditar na força democratizante destes, visto que ainda são encontrados muitos casos nos quais o governo utiliza sua força para impor demandas, escolher a agenda, dentre outros recursos de poder no jogo político. "Os encontros entre estado-sociedade nos conselhos têm sido afetados negativamente por uma grande recusa do estado em partilhar o poder de decisão" (Tatagiba, 2002, p.79).

Os conselhos ainda têm que vencer outros desafios, como por exemplo, o desafio financeiro que afeta diretamente na sua possibilidade de sobrevivência. Torna-se necessário garantir a independência, inclusive orçamentária interna, do próprio conselho, a fim de se superar essa possibilidade de constrangimento à participação popular e à descentralização efetivas das políticas públicas (Silva, 2001; Luchmann, 2011; Lavalle e Castello, 2008).

\section{Parcerias entre estado e organizações da sociedade civil: compassos e descompassados}

As parcerias entre governos e organizações da sociedade civil podem garantir a democratização das políticas públicas e ainda amplificar os impactos das políticas públicas em atuações locais. Além da potencialização dos resultados das políticas públicas, parte das iniciativas de inclusão social levadas a cabo por diferentes organizações da sociedade civil no Brasil tem se tornado um grande laboratório de experiências de promoção da cidadania e ampliação dos direitos sociais (Teodósio, 2001).

No entanto, a extrema heterogeneidade das organizações que compõem a sociedade civil no Brasil torna muito arriscado que se faça generalizações acerca de sua incidência na ampliação dos espaços participativos e democráticos no país. Além disso, na contemporaneidade parece haver uma idealização por parte da sociedade quanto ao potencial emancipatório e democrático de diferentes tipos de instituições que compõem a sociedade civil, notadamente as organizações não governamentais, associando-as sempre e automaticamente à defesa do interesse público, da justiça social e da democracia. Landim (2002), bem como Oliveira (2002), defendem a "desconstrução do conceito de ONG", pois essa expressão abrigaria tanto iniciativas de ampliação da cidadania e da participação popular, quanto velhas manifestações institucionalizadas de clientelismo, paternalismo e assistencialismo na sociedade brasileira atual. 
Essa realidade impõe que se estabeleça um olhar ainda mais crítico, detido e efetivamente capaz problematizar o papel das organizações da sociedade civil para a promoção da democracia participativa e as interações que estabelecem com o estado.

A partir dessa perspectiva, parcerias entre o estado brasileiro e as organizações da sociedade civil podem abrigar tanto iniciativas de ampliação da democratização do acesso aos bens e serviços públicos, quanto formas mais sofisticadas de manutenção do poder centralizado e excludente, apesar de aparentemente se assumirem como formas de articulação entre governo e sociedade civil comprometidas com a cidadania.

Vários grupos da sociedade civil demandam do estado uma atuação em rede mais efetiva e consistente, de forma a interagir de maneira mais horizontal com atores não estatais na discussão e provisão de políticas públicas e recorrer a eles para promover aberturas nos espaços organizacionais burocráticos dos órgãos de governo. Isso se caracteriza pelo "movimento externo em direção à formação e integração em blocos econômicos e um movimento interno, de descentralização, flexibilização e fortalecimento da sociedade civil, para compor um novo pacto e condições de governabilidade" (Carvalho, 2003, p. 1-2).

A atuação em redes pode ser uma característica significativa para consolidar o potencial das organizações da sociedade civil como agentes de democratização e modernização das políticas sociais brasileiras. Muitas organizações sem fins lucrativos aprenderam a trabalhar cooperativamente para potencializar suas chances de sobrevivência e superar sua limitações operacionais; essa atuação em redes traz novas formas de agregação de interesses e reivindicação de demandas (Teodósio, 2001; Minhoto e Martins, 2001).

No entanto, permanece uma importante desconfiança de que discurso governamental se faz mais enfático e decisivo em prol das redes da sociedade civil nas políticas públicas do que a realidade e efetividade da provisão de políticas públicas permite constatar no contexto brasileiro. O número de instituições assistencialistas e filantrópicas que se articulam em redes altamente hierarquizadas e centralizadoras no Brasil permanece como um sério desafio quanto a esse suposto papel modernizador contido na promessa das organizações da sociedade civil brasileiras. Redes parece ter se tornado uma expressão polissêmica, capaz de abrigar tanto articulações e relações entre estado e organizações da sociedade civil democráticas e participativas quanto autocráticas e centralizadas pelo governo. Ainda assim, cabe destacar os fundamentos por detrás das redes: 
É, talvez, nesse universo que parecem despontar os exemplos mais bem acabados do que seja de fato uma operação em rede, na qual cada um dos elementos estabelece uma relação de interdependência com os demais, em que a ação é cooperativa, o poder de decisão é descentralizado e as interações são regidas por regras e por valores democráticos (Martinho, 2001, p. 99).

O conceito de rede que se advoga quando se pensa em seu potencial como amplificador da participação popular está vinculado a uma nova forma de se pensar a gestão pública. Nesse sentido, entende-se por rede partes que se aglutinam formando mais que o todo, uma organização disforme, horizontal e sem hierarquia, onde a liderança é exercida de forma dinâmica, superando assim o paradigma piramidal de administração que se baseia na unidade de comando. É um modelo funcional que possui a característica de reunir e organizar elementos distintos, preservando-se a autonomia e condicionando a inter-relação por regras de convivência democráticas, assegurando o respeito às diferenças e valorizando a diversidade, obtendo um funcionamento conjunto e coordenado, visando à potencialização dos resultados (Martinho, 2001; Minhoto e Martins, 2001).

Da mesma forma, essa característica pode munir a ação pública de efetividade e competência. Através da rede pode-se socializar o poder, realizar negociações, flexibilizar, compatibilizar recursos e obter melhores resultados. Vale salientar que "somente a articulação/combinação de ações - entre políticas, intersetorial, intergovernamental e entre agentes sociais potencializa o desempenho da política pública" (Carvalho, 2003, p. 4).

Apesar do discurso em defesa da formação de redes capazes de modernizar a gestão pública brasileira ser louvável, na medida em que pode representar uma ampliação do número de atores que incidem no processo político das políticas públicas, não se pode entender a sua implementação e o seu desenvolvimento de forma autônoma em relação à trajetória histórica das relações entre estado e sociedade civil no país. Há o risco de novas formas de clientelismo e apropriação do espaço público pelo privado se manifestarem dentro e fora das redes sociais articuladas à provisão de bens e serviços públicos (Dupas, 2003). Assim, não só as articulações entre estado e organizações da sociedade civil, mas também a formação de redes podem se tornam em "compassos descompassados" na luta pela ampliação da democracia participativa na configuração das políticas públicas.

\section{Considerações finais}

Os problemas de ordem estrutural, sejam sociais, econômicos ou políticos, são resultado da ausência e da ineficiência do estado, do mercado e da própria 
sociedade civil organizada em apresentarem alternativas consistentes e viáveis diante da complexa realidade atual. Assim, muitos dos temas abordados nas políticas públicas têm sido encarados mais "como disfunções ou patologias sociais, do que como elementos estruturais das sociedades contemporâneas" (Tenório, 1999). A busca de parcerias para a solução de tais “disfunções” pode ser uma alternativa nesse contexto.

A descentralização não significa, a priori, a retirada do estado do âmbito social, podendo se constituir um passo relevante para garantir critérios de equidade e justiça social na provisão de políticas públicas no Brasil. Nesse contexto, o papel do estado passa a ser estratégico, orientando o desenvolvimento de diretrizes e prioridades sociais, passando-se a exigir muito mais habilidades gerenciais e políticas do que propriamente condições técnicas para execução de políticas.

A descentralização traz para o contexto político local sujeitos antes considerados como coadjuvantes ou simplesmente beneficiários. Assim passam a fazer parte da ação pública o estado, a sociedade civil, o mercado, a comunidade e o próprio público alvo da ação (Fischer, 1999). No entanto, o cenário brasileiro se constitui em um mosaico de possibilidades e ameaças à modernização da provisão de políticas públicas. Se de um lado está o governo, que precisa aprender a gerenciar compartilhando o poder, de outro estão as organizações da sociedade civil, que necessitam cada vez mais superar diferenças, avançar em suas práticas de gestão e também no próprio controle social sobre suas atividades, de forma a atuar no espaço público e alcançar os resultados esperados para sua atuação.

O ponto mais relevante a se refletir é que as muitas das organizações da sociedade civil ainda não se encontram aptas a atuar de forma sistêmica na geração de políticas públicas. Enquanto em parcelas significativas das organizações da sociedade civil a atuação em rede faz parte do próprio nascimento dessas organizações, para outras parcelas desse setor a expressão redes, quanto é adotada, descaracteriza-se totalmente em relação ao seu papel como instrumento de participação e democratização das políticas públicas.

Pensando para além da mera provisão de bens e serviços públicos, seria preciso para o avanço da democracia participativa no país que as organizações da sociedade civil se fortaleçam como agentes ativos do exercício do poder político, deliberação sobre políticas públicas e produção de bens e serviços sociais. Além disso, não podem perder sua intensidade como entes políticos responsáveis pelo desenvolvimento de uma cultura política mais favorável à participação popular e à cidadania. Isso pode se dar pela contestação das formas institucionalizadas de se fazer política no país e pela proposição de inovações 
no trato dos problemas sociais. No entanto, a ênfase de vários processos de modernização do estado, operados tanto no nível federal quanto estadual e sobretudo municipal no Brasil, parece residir no estímulo à proliferação de organizações da sociedade civil mais vocacionadas à provisão de serviços sociais e menos orientadas para os embates políticos. Tudo isso acaba por gerar dinâmicas sociopolíticas, inclusive pelos recorrentes esforços que essas organizações precisam desenvolver para permanecer qualificadas como instâncias de provisão de serviços públicos, que criam importantes obstáculos ao próprio fortalecimento da sociedade civil no país e com consequências perigosas para a manutenção e ampliação da democracia participativa.

O "futuro do futuro" da descentralização e das parcerias com as organizações da sociedade civil, que já se anuncia nos tempos presentes, reserva boas promessas e sérios motivos para apreensão. Ao pesquisador que busca a utópica isenção científica, cabe formular novas perguntas de investigação e novos olhares sobre antigos e novos dilemas da participação popular nas políticas públicas brasileiras, esperando que as respostas sejam mais promissoras dos que as que podemos enxergar nos tempos atuais. Ao contrário do que professam as visões fatalistas sobre uma suposta inércia e permanência da cultura política brasileira, sempre colocando-a em um plano inferior àquelas presentes nas democracias dos países centrais pelos seus vícios democráticos, os dramas e tramas da democracia participativa se renovam e ganham novas dimensões ao longo da trajetória de interações entre estado e sociedade civil. Assim, novas agendas de pesquisa sobre participação popular e democratização se fazem ainda mais promissoras, na medida em que possam incorporar elementos contextuais da ambiência política brasileira dos últimos anos no Brasil, notadamente à tomada das ruas pela população em meados de 2013, para compreender quais caminhos as relações entre estado e sociedade civil vão trilhar.

\section{Referências}

ARRETCHE, M. T. S. Mitos da descentralização: mais democracia e eficiência nas políticas públicas? Revista Brasileira de Ciências Sociais, v. 11, n. 31, p. 44-66, 1996.

ARRETCHE, M. T. S. O Sistema de proteção social brasileiro em direção a um modelo descentralizado. São Paulo em Perspectiva, v. 2, n. 3, p. 20-31, 1997.

AZEVEDO, S.; PRATES, A. A. P. Planejamento participativo, movimentos sociais e ação coletiva. Ciências Sociais Hoje. São Paulo: Ed. Revista dos Trinunais, p. 122-152, 1991.

BARAT, Josef. O estado brasileiro como refém das políticas de curto prazo. Cadernos Fundap, n. 22, p. 62-69, 2002. 
CARVAlHO, C. A. P. de. Preservar a identidade e buscar padrões de eficiência: questões complementares ou contraditórias na atualidade das organizações não governamentais? Revista Rets, v. 2, n. 93 <www.rits.org.br/rets> (13 fev. 2003).

CARVALHO, J. M. Cidadania no Brasil: o longo caminho. Rio de Janeiro: Civilização Brasileira, 2008.

COHN, A. Os governos municipais e as políticas sociais. In: J. A. Soares; S. CacciaBrava (Orgs.). Os desafios da gestão municipal democrática. São Paulo: Cortez, 1998. p. 173-192.

DEMO, P. Cidadania pequena: fragilidades e desafios do associativismo no Brasil. Campinas: Autores Associados, 2001.

DINIZ, E. Voto e máquina política: patronagem e clientelismo no Rio de Janeiro. Rio de Janeiro: Paz e Terra, 1982.

DRAIBE, S. M. B. As políticas sociais e o neoliberalismo. Revista USP, n. 17, p. 86-101, 1993 b.

DUPAS, G. Tensões contemporâneas entre o público e o privado. São Paulo: Paz e Terra, 2003.

FERNANDES, F. Que tipo de república? São Paulo: Globo, 2007.

FERRAREZI, E. Organizações da sociedade civil de interesse público e a agenda de reformas das políticas sociais. Aminoácidos, v. 3, p.77-85, 2002.

FISCHER, R. M. Desafios da parceria governo e terceiro setor. Primeiro Encontro da Rede de Pesquisas sobre o Terceiro Setor na América Latina e Caribe, Rio de Janeiro: Centro de Estudos da Escola de Serviço Social da Universidade Federal do Rio de Janeiro, 1999.

GÓMEZ, J. M. Reinventando a comunidade politica, globalizando a cidadania. Petrópolis: Vozes, 2000.

GOHN, M. G. O protagonismo da sociedade civil: movimentos sociais, ONGs e redes solidárias. São Paulo: Cortez, 2005.

GOHN, M. G. Conselhos gestores e participação sociopolitica. São Paulo: Cortez, 2001.

LANDIM, L. Múltiplas identidades das ONGs. In: S. Haddad (Org.). ONGs e universidades. São Paulo: Abong, 2002. p. 17-50.

LAVALLE, A. G.; CASTELlO, G. Sociedade civil, representação e a dupla face da accountability: cidade do México e São Paulo. Caderno CRH, v. 21, n. 52, p. 67-86, 2008 .

LUCHMANN, L. H. Associações, participação e representação: combinações e tensões. Lua Nova, v. 84, p. 353-364, 2011.

MARTINHO, C. O projeto das redes: horizontalidade e insubordinação. Aminoácidos, v. 2, p. 95-105, 2001.

MINHOTO, L. D.; MARTINS, C. E. As redes e o desenvolvimento social. Cadernos Fundap, v. 22, p. 74-80, 2002. 
NOGUEIRA, M. A. Um estado para a sociedade civil: temas éticos e políticos da gestão democrática. São Paulo: Cortez, 2004.

NUNES, E. A gramática política no Brasil. Rio de Janeiro: Jorge Zahar, 1999.

OLIVEIRA, F. Entre a complexidade e o reducionismo: para onde vão as ONGs de democratização? In: S. Haddad (Org.). ONGs e universidades. São Paulo: Abong, 2002. p. 51-62.

SILVA, I. G. Democracia e participação na "reforma" do estado. São Paulo: Cortez, 2003.

TENÓRIO, F. G. Um espectro ronda o terceiro setor: o espectro do mercado. II Encontro da Rede Latino-Americana e do Caribe da Sociedade Internacional de Pesquisa do Terceiro Setor, Chile: FGV, 1999.

SILVA, M. K. Construção da participação popular: análise comparativa de processos de participação social na discussão pública do orçamento em municípios da Região Metropolitana de Porto Alegre, RS. (Dissertação de mestrado). Universidade Federal do Rio Grande do Sul, Brasil, 2001.

TEODÓSIO, A. S. S. Pensar pelo avesso o terceiro setor: mitos, dilemas e perspectivas da ação social organizada no Brasil. In: M. Stengel et al. (Orgs.). Políticas públicas de apoio sociofamiliar: curso de capacitação de conselheiros municipais e tutelares. Belo Horizonte: Pontifícia Universidade Católica de Minas Gerais, 2001. p. 85-124.

Recebido em: 17 fev. 2012

Aprovado em: 18 nov. 2013

Autor correspondente:

Armindo dos Santos de Sousa Teodósio

PPG em Administração

Av. Itaú, 525 - Dom Cabral

30535-012 Belo Horizonte, MG 